That hope has logic on its side, and it is not misplaced. In February, authorities in GM-hostile Germany told Cibus that they would not consider products created by gene editing as GM, but as products of conventional plant breeding. However, with new battle lines already being drawn, broader approval and acceptance are unlikely to be so simple.

The first battle for GM crops in Europe is currently drawing to an unsatisfactory close. EU legislation from 2001 dictates that the European Food Safety Authority (EFSA) must carry out a scientific risk assessment of any GM strain submitted for authorization. Member states must then vote on whether to pass it, obliging all of them to permit the crop's cultivation if it is approved.

But these votes have almost never yielded the required majority for or against any strain given the EFSA green light. And the European Commission has never dared to exercise its right to enforce a positive decision in cases of impasse. Instead, it has proposed new rules, which came into force last week, allowing EU member states to opt out of a requirement to allow cultivation on non-scientific grounds.

Although it is smart politics, the rule will not be enough to break through the authorization impasse, because all nations must still vote, and a qualified majority must be reached. So, in the next few weeks, the commission will propose further legislation that is likely to allow member states to opt out of the authorization process too. This could finally get the system going again, and give GM-friendly countries such as Spain a wider range of GM crops to choose from.

Meanwhile, science has moved on. Plants without foreign genes can now be created with a variety of methods and technologies that precisely tweak or change the regulation of a native gene. Such plants should reassure anti-GM lobbies that criticize the moral right of scientists to 'play God', and the alleged instability of foreign genes. But environmental groups such as Greenpeace seem far from convinced. In January, several groups wrote an open letter to the commission insisting that new methods that change DNA structure or interfere with gene regulation in any way should also be subject to the EU's tight
GM regulations. They argue that the precautionary principle should continue to apply - and that because of the enhanced abilities of the technologies, the safety bar should in fact be raised.

The commission is again playing for time. In 2007, it appointed an expert panel to advise it on the ever-expanding plant-breeding toolbox. The panel's report was submitted in 2012 but never published. The commission now says that it has set in motion a "thorough legal analysis"
"The European Commission is again playing for time." of the definition of 'GM organisms' in its own legislation, and of the criteria for excluding certain technologies. The conclusions of the analysis, it warns, "cannot be anticipated".

Most plant scientists consider the new tools to be helpful extensions to normal plantbreeding practice. In many cases, they say, the plant products are indistinguishable from the original plants and are intrinsically even safer than GM plants. Two years ago, the European Academies Science Advisory Council, an umbrella group for national academies in Europe, argued that the time had come for regulators to abandon their fixation on plant technologies and instead carry out risk assessments on the individual plant products. In February, the European Plant Science Organisation, an independent body representing more than 220 research institutes and universities from 28 European countries, as well as Australia, Japan and New Zealand, reiterated the message.

Late last month, the Leopoldina, Germany's national academy of sciences, published a similar position paper in the hope of influencing its government, as the country deliberates anew the legal environment of its GM regulations. Both Germany and the commission are watching and waiting. In their letter to Cibus, the German authorities noted that their statement of readiness to consider products of gene editing as non-GM would be invalidated if the European Commission were finally to decide otherwise.

As Europe's first battle on GM staggers to an uneasy truce, a second — and perhaps more important one - is approaching.

\section{Lunar affairs}

\section{A study in Nature adds a dramatic twist to the backstory of a neighbour we thought we knew.}

\section{$\mathrm{I}$} $\mathrm{n}$ the stories of many human cultures, the Solar System is something of a family affair. The Norse people and the Incas of South America believed that the Sun and the Moon were brother and sister. A Native American myth has them as husband and wife (although the husband wants to eat his children, the stars). The Moon as a mother is a common theme.

Now scientists have suggested a rival celestial tale with a twist that is more common to terrestrial television dramas: the sudden appearance of a long-lost sibling. The early Earth had a near-identical geological twin, they say. The two young planets, of course, had a falling out and the twin vanished. But before it did so, it saddled Earth with an orbiting Moon-child.

The the origin of the Moon is a classic story that has been told many times. The latest version - written in a research paper on page $212-$ still has some plot holes. But it is a cracking tale.

The time: some 4.5 billion years ago, in the earliest days of the Solar System. The place: hostile. A long time ago, if you like, in a galaxy not very far away. Thousands of adolescent protoplanets whizz around the Sun, bashing into each other, some breaking into smaller pieces and forming others as they soak up the freed materials. One of these protoplanets, lying not too far from the Sun and not too close, is what we now call Earth.

Enter, stage left, protoplanet Theia. Smaller than proto-Earth, it was raised in a similar neighbourhood. A chance meeting set the two on a collision course. The meeting is violent, and - here it helps if you imagine the most gravelly cinematic voice-over you can manage - life for both will never be the same again.

Theia becomes a giant cloud of dust infused with bits spewed from the injured proto-Earth, which quickly comes together to form the Moon. Earth gains a dependant.

The script might sound familiar; the plot more of a remake than of anything original. But here is the difference. Previously, many planetary scientists considered that it was too much of a stretch to say that young Theia and Earth were so closely related. It is much more plausible, given the chaos of the time, to present Theia as a random stranger. But that creates a continuity error: the mineral composition of rocks retrieved from the Moon is eerily similar to those of Earth.

Either Theia and Earth are related, or our best models of how the Moon formed are wrong. But if they are related, then why is it that the other bodies in the Solar System that we have studied seem to be so different from each other? What are the chances, given the number of objects out there at the time, that proto-Earth would be hit by a near clone?

The latest study runs computer simulations of those early days, to investigate the possible backstories of the major characters, including how and where they formed and their probable orbits. (A note to film directors: this bit is probably best presented as a montage.) The number crunching offers a realistic script: there is a one-in-five chance that proto-Earth and Theia could have formed at about the same distance $\triangle$ NATURE.COM To comment online, click on Editorials at: go.nature.com/xhunqv from the Sun, so from the same stuff, and then run into each other to make the Moon. True, it is not a cut-and-dried ending that ties up all the loose ends before the credits roll. But all the best stories leave room for a sequel. 